\title{
THE GENETIC CONTROL OF GIBBERELLIC ACID INSENSITIVITY AND COLEOPTILE LENGTH IN A "DWARF" WHEAT
}

\author{
MICHAEL D. GALE, C. N. LAW, G. A. MARSHALL and A. J.WORLAND \\ Plant Breeding Institute, Maris Lane, Trumpington, Cambridge
}

Received 10.viii.74

\begin{abstract}
SUMmarY
In hexaploid wheat (Triticum aestivum) analysis of the $\mathrm{F}_{2}$ generation of the cross of Minister Dwarf and Chinese Spring showed that insensitivity to gibberellic acid, a characteristic of Minister Dwarf and other dwarf wheats, was determined by a single gene, $\mathrm{Gai}_{3}$. The short coleoptiles, which are also a feature of these dwarf wheats, was also identified as being predominantly controlled by a single gene which was probably identical to the gene $\mathrm{Gai}_{3}$.

$\mathrm{F}_{2}$ monosomic analysis located $\mathrm{Gai}_{3}$ on chromosome $4 \mathrm{~A}$ and demonstrated that the allele of $\mathrm{Gai}_{3}$ for insensitivity was an active allele rather than a deletion or a null allele, since plants nullisomic for chromosome $4 \mathrm{~A}$ were not insensitive. The transmission rates of 20 chromosome gametes deficient for chromosome $4 \mathrm{~A}$ was found to be higher than normally expected.

$\mathrm{Gai}_{3}$ was also epistatic to genes for increasing coleoptile length carried by other chromosomes than $4 \mathrm{~A}$, indicating that selection for acceptable coleoptile lengths in breeding programmes may be difficult in the presence of $\mathrm{Gai}_{3}$.
\end{abstract}

\section{INTRODUGTION}

Gibberellic ACID (GA) insensitivity for plant height in dwarf wheats, Triticum aestivum $(2 n=6 x=42)$, has been described by Allan, Vogel and Craddock (1959), and has been shown to be associated with high endogenous levels of the hormone by Radley (1970). Other aspects of the GA insensitive reaction were described by Gale and Marshall (1973a) who showed that the dwarf varieties, Norin 10-Brevor 14, Tom Thumb and Minister Dwarf displayed a similar lack of response to GA in plant height, but an increased response in tiller production, the reverse of the reduced tillering response found in tall GA-sensitive varieties. Also both Minister Dwarf and Tom Thumb failed to produce $\alpha$-amylase in germinating grain in response to GA treatment, whereas Norin 10-Brevor 14, like most other wheat genotypes, was stimulated to produce the enzyme.

Norin 10-Brevor 14 has been used as a source of dwarfism in the development of many of the successful semi-dwarf wheat varieties which are widely grown throughout the world. Probably all the semi-dwarf wheats derived from this source are GA-insensitive in aerial tissues, so that an understanding of the genetic and physiological relationships which exist between dwarfism, GA-insensitivity and other associated characters is of considerable significance in plant breeding.

This paper describes experiments designed to investigate the inheritance of the GA-insensitivity of Minister Dwarf and the relationships of this character to short coleoptiles which is another correlated feature of dwarf wheats. 


\section{Materials AND Methods}

Minister Dwarf (MD) and the monosomic series of Chinese Spring (CS), a variety sensitive to exogenous GA, were used in these studies.

MD was obtained from a hybrid of Triticum spelta and "Tom Pouce", backcrossed on to the variety Minister (P. Derenne, personal communication). "Tom Pouce" was derived from an old English variety "Hybrid Carter G" as described by Zeven (1969).

The method of monosomic analysis (Sears, 1953) was employed to study the genetic control of the differences in response to GA expressed by MD and C.S. This method permits the recognition of the chromosome carrying the gene or genes responsible for a character difference by comparing, in the case of dominant genes, the segregation of each of the $21 \mathrm{~F}_{2}$ monosomic families with the normal or control $F_{2}$. For the critical $F_{2}$ monosomic family, derived from an $F_{1}$ monosomic in which the hemizygous donor chromosome carries the gene or genes under investigation, most of the $\mathrm{F}_{2}$ progeny should have the donor varieties phenotype. For the non-critical $\mathrm{F}_{2}$ monosomic families, the segregation of this gene or genes will be as in a normal $\mathrm{F}_{2}$. Departures from the normal $\mathrm{F}_{2}$ therefore indicate the chromosome carrying the gene or genes concerned.

The method has worked well in the analysis of character differences which are under the control of a few genes whose effects are readily recognisable (Unrau, 1950; Macer, 1966).

MD was crossed to each of the 21 monosomic lines of CS and monosomic $F_{1}$ hybrids were selected by means of chromosome counts made on root-tip squashes stained by the Feulgen procedure. The resulting $F_{1}$ monosomics, as well as $F_{1}$ disomic hybrids were then selfed and $F_{2}$ grains obtained from all of the lines except $\mathrm{CS} 2 \mathrm{~B} / \mathrm{MD}$ which was sterile.

The monosomic analysis experiment was carried out on plots of 50 unselected grains from each of the $20 \mathrm{~F}_{2}$ monosomic families, seven $\mathrm{F}_{2}$ control families and the two parents, $\mathrm{MD}$ and CS. The grain was sown in vermiculite, moistened with culture solution (Austin and Maclean, 1972) and grown for 3 days at $2^{\circ} \mathrm{C}$ to ensure even germination and then for 6 days at $18^{\circ} \mathrm{C}$ and 3000 lux. Coleoptile lengths were scored at this time and then the culture solution was supplemented with GA (Berelex, Plant Protection Ltd.) at $10 \mathrm{ppm}$. Seedlings were scored as responsive or insensitive after a further 10 days.

\section{Results}

\section{(i) GA insensitivity}

Following treatment with GA, plants could be classified readily into responders and insensitives. Responders $(R)$ gave a distinctive phenotype and produced thin stems with elongated internodes and leaves.

A preliminary experiment in which $99 \mathrm{~F}_{2}$ progeny of the cross $\mathrm{MD} \times \mathrm{CS}$ gave 79 insensitive $(\mathrm{I}): 29$ responsive $(\mathrm{R})$ seedlings, indicated that the character was under the control of a single dominant gene, henceforth designated as $\mathrm{Gai}_{3}\left(\chi^{2}{ }_{\{1\}}=0 \cdot 19, \mathrm{P}>0 \cdot 2\right)$. In a further experiment to assess the relationship of GA insensitivity with coleoptile length, embryos from $40 \mathrm{~F}_{2}$ seeds from the $\mathrm{MD} \times \mathrm{CS}$ cross were grown in the dark on agar, scored for coleoptile length after 6 days and then transplanted into pots. Embryos 
were preferred for this investigation since previous experiments (Gale and Marshall, 1975) had shown that the GA-insensitivity of MD can affect coleoptile and early seedling growth via an effect on mobilisation of endosperm reserves during germination.

Measurement of coleoptile lengths indicated that the seedlings could be classified into two distinct groups of 30 short $(30-60 \mathrm{~mm})$ to 10 long (75$95 \mathrm{~mm}$ ) indicating the segregation of a single gene affecting coleoptile length. On applying GA, only the 10 seedlings with long coleoptiles responded to give elongated internodes, whereas all the short coleoptile seedlings were

TABle 1

$G A$-responsive $(R)$ and Ga-insensitive $(I)$ progeny and coleoptile lengths $(\mathrm{mm})$ of $F_{2}$ control and $F_{2}$ monosomic families

\begin{tabular}{|c|c|c|c|c|c|}
\hline Family & $\mathrm{R}: \mathrm{I}$ & $\bar{x}_{\mathrm{R}}$ & $\bar{x}_{\mathrm{I}}$ & $\begin{array}{c}\text { Chromosomal } \\
\text { effects }\end{array}$ & $\begin{array}{c}\text { Interaction } \\
\text { effects }\end{array}$ \\
\hline Control $F_{2}$ & $71: 251$ & $25 \cdot 39$ & $19 \cdot 31$ & - & - \\
\hline $\mathrm{CS} 1 \mathrm{~A} / \mathrm{MD}$ & $13: 35$ & $26 \cdot 00$ & $20 \cdot 20$ & 1.49 & -0.28 \\
\hline CS1BM/D & $10: 40$ & $26 \cdot 80$ & $20 \cdot 83$ & $2 \cdot 92$ & $-0 \cdot 11$ \\
\hline $\mathrm{CS} 1 \mathrm{D} / \mathrm{MD}$ & $18: 32$ & $28 \cdot 17$ & $19 \cdot 91$ & $3 \cdot 37 * *$ & $2 \cdot 18$ \\
\hline $\mathrm{CS} 2 \mathrm{~A} / \mathrm{MD}$ & $7: 43$ & $24 \cdot 14$ & $19 \cdot 60$ & -0.95 & $-1 \cdot 55$ \\
\hline $\mathrm{CS} 2 \mathrm{D} / \mathrm{MD}$ & $17: 32$ & $23 \cdot 82$ & $15 \cdot 94$ & $-4 \cdot 94 * * *$ & $-1 \cdot 80$ \\
\hline CS3A/MD & $9: 39$ & $30 \cdot 44$ & $21 \cdot 56$ & $7 \cdot 30 * * *$ & $2 \cdot 79 * *$ \\
\hline $\mathrm{CS} 3 \mathrm{~B} / \mathrm{MD}$ & $11: 32$ & $26 \cdot 18$ & $19 \cdot 34$ & $0 \cdot 82$ & 0.75 \\
\hline $\mathrm{CS} 3 \mathrm{D} / \mathrm{MD}$ & $13: 31$ & $27 \cdot 77$ & $20 \cdot 71$ & $3 \cdot 78 * *$ & 0.97 \\
\hline $\mathrm{CS} 4 \mathrm{~A} / \mathrm{MD}$ & $5: 43^{*}$ & $29 \cdot 00$ & $19 \cdot 71$ & - & - \\
\hline $\mathrm{CS} 4 \mathrm{~B} / \mathrm{MD}$ & $7: 43$ & $25 \cdot 29$ & $20 \cdot 23$ & $0 \cdot 82$ & -1.03 \\
\hline $\mathrm{CS} 4 \mathrm{D} / \mathrm{MD}$ & $15: 35$ & $22 \cdot 93$ & $15 \cdot 86$ & $-5 \cdot 91 * * *$ & 0.98 \\
\hline $\mathrm{CS} 5 \mathrm{~A} / \mathrm{MD}$ & $14: 33$ & $31 \cdot 50$ & $21 \cdot 30$ & $8 \cdot 10 * * *$ & $4 \cdot 11 * * *$ \\
\hline CS5B/MD & $14: 35$ & $30 \cdot 71$ & $20 \cdot 74$ & $6 \cdot 45 * * *$ & $3 \cdot 88 * * *$ \\
\hline $\mathrm{CS} 5 \mathrm{D} / \mathrm{MD}$ & $9: 39$ & $31 \cdot 00$ & $21 \cdot 59$ & $7 \cdot 89 * * *$ & $3 \cdot 32$ \\
\hline $\mathrm{CS} 6 \mathrm{~A} / \mathrm{MD}$ & $13: 37$ & $27 \cdot 92$ & $20 \cdot 73$ & $3.95 * *$ & $1 \cdot 10$ \\
\hline $\mathrm{CS} 6 \mathrm{~B} / \mathrm{MD}$ & $11: 35$ & $27 \cdot 64$ & $21 \cdot 83$ & $4 \cdot 77 * * *$ & $-0 \cdot 28$ \\
\hline $\mathrm{CS} 6 \mathrm{D} / \mathrm{MD}$ & $14: 31$ & $28 \cdot 07$ & $20 \cdot 35$ & $3 \cdot 72$ & $1 \cdot 63$ \\
\hline CS7A/MD & $12: 37$ & $25 \cdot 33$ & $19 \cdot 38$ & $0 \cdot 00$ & $-0 \cdot 14$ \\
\hline CS7B/MD & $14: 35$ & $28 \cdot 07$ & $19 \cdot 69$ & $3.06 * *$ & $2 \cdot 29$ \\
\hline $\mathrm{CS} 7 \mathrm{D} / \mathrm{MD}$ & $14: 34$ & $28 \cdot 86$ & $19 \cdot 26$ & $1 \cdot 42$ & 1.51 \\
\hline $\mathrm{CS}$ & - & $27 \cdot 55$ & - & - & - \\
\hline MD & 一 & - & $15 \cdot 35$ & - & - \\
\hline
\end{tabular}

insensitive. There is thus an association between GA response and coleoptile length which is independent of the effect of GA on endosperm mobilisation. The complete association also suggests that the single genes affecting these two characters are either the same or are closely linked.

The results obtained from the $\mathrm{F}_{2}$ monosomic analysis, classified as the number of $\mathrm{R}$ and $\mathrm{I}$ progeny within each monosomic family and the mean coleoptile lengths of these two types of progeny, are given in table 1.

Since a single dominant gene $\mathrm{Gai}_{3}$ is responsible for the distinction between $\mathrm{R}$ and $\mathrm{I}$ seedlings, then only one of the $\mathrm{F}_{2}$ monosomic families should show an excess of $I$ progeny compared with the control $F_{2}$. For this critical $\mathrm{F}_{2}$ monosomic family the only $\mathrm{R}$ progeny expected, assuming that $\mathrm{Gai}_{3}$ is expressed in the hemizygous condition, would be nullisomic and deficient for the chromosome carrying $\mathrm{Gai}_{3}$. Normally such nullisomics are rare and in CS constitute about 3 per cent of the progeny of a monosomic (Sears, 1953). 
Examination of the segregation into $\mathrm{R}$ and I progeny indicates that none of the monosomic families depart from the control $\mathrm{F}_{2}$ in showing an excess of insensitives. Only three families stand out, CS2A/MD, CS4A/MD and CS4B/MD, as having low frequencies of responders and none of these families depart significantly from the control, although CS4A/MD gives a ratio which is significantly different from the expected $3: 1$ ratio $\left(\chi^{2}{ }_{\{1\}}=5 \cdot 44\right.$, $\mathrm{P}<0.02)$. This can only be interpreted to mean that either $\mathrm{Gai}_{3}$ is not completely effective in the hemizygous condition or the transmission of 20 chromosome gametes giving rise to responsive nullisomics is much higher than expected in the critical $\mathbf{F}_{\mathbf{2}}$ monosomic family.

To test this latter possibility the $\mathrm{R}$ progeny in these three families were scored for their chromosome numbers. For CS2A/MD and CS4B/MD both disomic and monosomic progeny were found, whereas for CS4A/MD the four R progeny successfully scored had 40 chromosomes and were therefore presumably nullisomic for chromosome $4 \mathrm{~A}$. A repeat experiment on the $\mathrm{CS} 4 \mathrm{~A} / \mathrm{MD} \mathrm{F}_{2}$ family was consequently carried out and gave $35 \mathrm{I}: 12 \mathrm{R}$ in which the 10 successfully scored plants from the $\mathrm{R}$ group were found to be nullisomic.

It is clear therefore that $\mathrm{Gai}_{3}$ is located on chromosome $4 \mathrm{~A}$ and that the high incidence of responders in the $\mathrm{F}_{\mathbf{2}}$ monosomic for this chromosome is due to an abnormally high transmission of nullisomic gametes.

\section{(ii) Coleoptile length}

$\mathrm{Gai}_{3}$ or a closely linked gene also accounts for a major part of the variation in coleoptile length between the two varieties. Other genes carried by chromosomes other than $4 \mathrm{~A}$ may however affect this character and contribute to the differences between the varieties.

The location of some of these genes may be attempted by comparing the mean coleoptile lengths of each of the monosomic $F_{2}$ families with the mean of the control $F_{2}$. Any differences that occur between these means would indicate that either different alleles or alterations in chromosome dosage or both were responsible.

A second comparison which is perhaps more interesting and informative can also be made from the separation of coleoptile lengths of untreated progeny into the two groups, $\mathrm{R}$ and I, based upon their behaviour following treatment with GA. This separation permits a test to be made of the effect of segregation at the $\mathrm{Gai}_{3}$ locus on the variation within each of the monosomic families. If the $\mathrm{R}$ and $\mathrm{I}$ groups within any monosomic $\mathrm{F}_{2}$ have larger or smaller differences in mean coleoptile length than the $\mathrm{R}$ and $\mathrm{I}$ groups in the control, then this indicates that $\mathrm{Gai}_{3}$ must interact with the genes affecting coleoptile length on the particular chromosome under test irrespective of whether the differences from the control are due to chromosome dosage or allelism.

The mean coleoptile lengths of untreated plants at 6 days partitioned according to their subsequent classification as $\mathrm{R}$ or I are shown as $\bar{x}_{\mathrm{R}}$ and $\bar{x}_{\mathrm{r}}$ in fig. 1. The first comparison, which estimates chromosomal effects due to allelic variation and/or chromosome dosage, is given by the mean of an $\mathrm{F}_{2}$ monosomic family minus the $\mathrm{F}_{2}$ control family, i.e. $\left(\bar{x}_{\mathrm{R}}+\bar{x}_{\mathrm{I}}-\bar{x}_{\mathrm{R}}-\bar{x}_{\mathrm{IC}}\right)$ where $\bar{x}_{R C}$ and $\bar{x}_{I C}$ refer to the mean of the $\mathrm{R}$ and I progeny of the control $F_{2}$ respectively. The second or interaction comparison is derived from 
$\bar{x}_{\mathrm{R}}-\bar{x}_{\mathrm{I}}-\bar{x}_{\mathrm{R}}+\bar{x}_{\mathrm{IC}}$. The values and significance of both these comparisons for each monosomic family are presented in table 1 .

In determining the levels of significance for each of these comparisons, within family variances for each of the $\mathrm{F}_{2}$ monosomics were used except in the case of the $\mathrm{F}_{2}$ disomic control where seven separate families were grown. The within family variances for each of these control $F_{2}$ 's were however homogeneous whereas the between family differences were found not to differ from the within family variances. A pooled estimate of between and within family variances was therefore used in the case of the control $F_{2}$. Throughout a modified " $t$ " test (Cochran, 1964) was applied in cases of borderline significance and, because of the large number of comparisons, an acceptable level of significance of $\mathrm{P}<0.01$ was adopted.

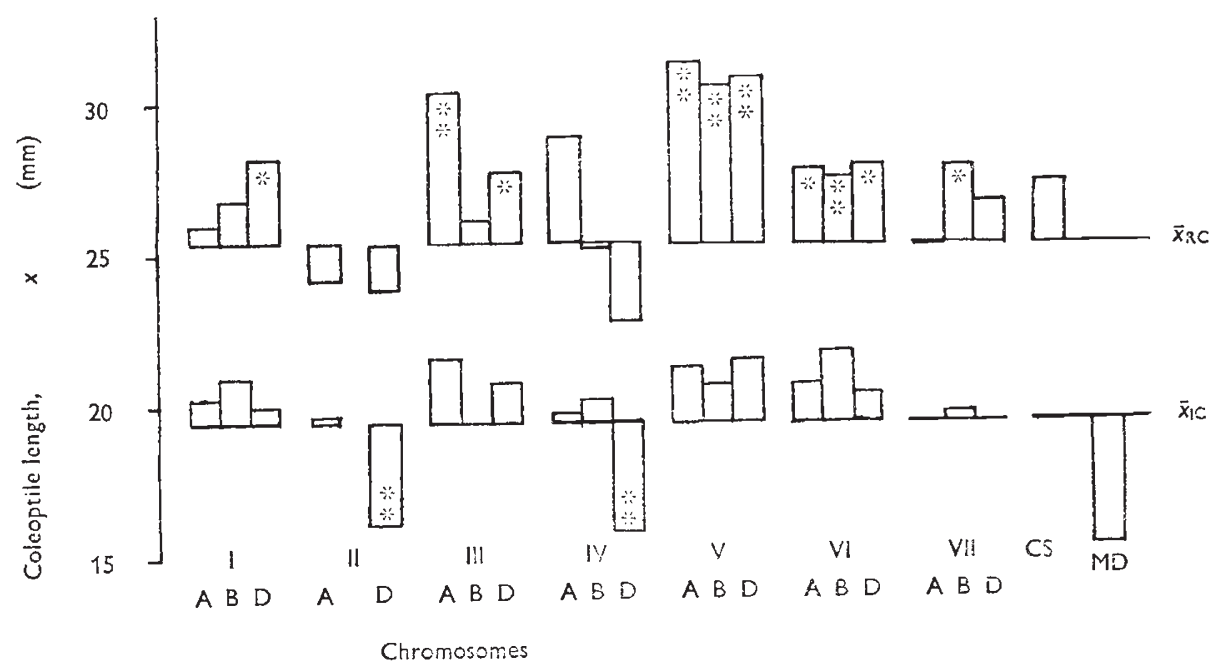

Fig. 1.-Mean coleoptile lengths for responsive and insensitive classes within $\mathrm{F}_{2}$ monosomic families, compared with control $\mathrm{F}_{2}$ means. (Note: * $\mathrm{P}<0.01$ and ** $\mathrm{P}<0.001$.)

Eleven of the $\mathrm{F}_{2}$ monosomic families departed significantly from the control $F_{2}$ in mean coleoptile length. Only $\mathrm{CS} 2 \mathrm{D} / \mathrm{MD}$ and $\mathrm{CS} 4 \mathrm{D} / \mathrm{MD}$ gave mean coleoptile lengths less than the control. It is possible therefore that these chromosomes of MD carry alleles which reduce coleoptile length compared with their alleles in CS. On the other hand, the marked increases in coleoptile length obtained for the remaining significantly different families suggest that chromosome dosage rather than allelic differences are implicated. If this is correct then it is reasonable to suppose that each of these chromosomes carry genes which inhibit coleoptile length and it is their removal which results in the increased coleoptile lengths observed.

Only three chromosomes, $3 \mathrm{~A}, 5 \mathrm{~A}$ and $5 \mathrm{~B}$, gave significant interactions with the segregation at the $\mathrm{Gai}_{3}$ locus, although the high interaction estimate for chromosome 5D points to all the chromosomes of this group being involved. Moreover, all the interactions were positive indicating that $\mathrm{Gai}_{3}$ reduces the effects of the genes, carried by these chromosomes, for increasing coleoptile length. This could arise either from the enhanced expression of promoters in the absence of $\mathrm{Gai}_{3}$ or the enhanced expression of inhibitors in its presence. Since, as mentioned in the previous paragraph, reduced 
chromosome dosage would appear to be responsible for the increases in mean coleoptile length exhibited by these families, the enhanced effect of inhibitors is probably correct.

\section{Discussion AND CONClusions}

The monosomic analysis clearly indicates that a gene $\left(\mathrm{Gai}_{3}\right)$ for insensitivity to GA is located on chromosome 4A. The association of this character with coleoptile length indicates that these characters could be controlled by the same gene and suggest that the reduced coleoptile lengths could arise as a consequence of abnormal GA-metabolism.

However, the unequivocable proof that associations between two or more characters are due to the pleiotropic effects of a single gene is extremely difficult to establish. For the sample sizes used in the experiments described, it can be shown that recombinant lines need not appear even though two linked genes, having a recombination frequency between them of 5 per cent, were responsible for the separate control of the two characters under investigation. The results presented here are therefore inconclusive on this point.

However, other data available from crosses of MD with tall wheat varieties, in which over a 1000 progeny were classified with respect to coleoptile length and GA insensitivity, gave no evidence of a breakdown in the association between these two characters. A combination of all the data relating to $\mathrm{MD}$ crosses reduces the admissible recombination value on the hypothesis of two genes to a value as low as 0.025 per cent. This is very suggestive that pleiotropy rather than linkage is responsible for the association.

On the other hand, whilst it is clear that a genetic explanation of the association between these two characters is forthcoming from these experiments, it is not clear how these characters relate to the dwarf nature of adult MD. Coleoptile length and final plant height are often highly correlated (Allan and Vogel, 1964). Also the location of the dwarfing gene in Tom Thumb, a variety which is similar in phenotype to $\mathrm{MD}$, on chromosome $4 \mathrm{~A}$ by Morris, Schmidt and Johnson (1972) suggests that all these characters could be causally related and determined by the gene $\mathrm{Gai}_{3}$. $\mathrm{Hu}$ (1974), however, from a study of dwarf $\times$ tall wheat crosses involving Tom Thumb, found two $\mathrm{F}_{4}$ lines that were apparently homozygous for the genes for dwarfism but which segregated for GA insensitivity. He thus concluded that the two characters were under separate control. There is thus some evidence which suggests that the "dwarf" character has a separate genetic control from GA-insensitivity and coleoptile length and it may be possible to produce "dwarf" and tall plants which are sensitive and insensitive respectively.

It is also evident from the results presented here, that $\mathrm{Gai}_{3}$ has an epistatic effect on genes, distributed on chromosomes other than $4 \mathrm{~A}$, for increasing coleoptile length. Positive selection for coleoptile length in the presence of $\mathrm{Gai}_{3}$ will consequently not be as effective as in its absence. This could have important consequences on crop establishment if GA insensitivity proves to be an advantage in varietal improvement. It could be even more important if $\mathrm{Gai}_{3}$ has a similar effect on genes for increasing final plant height, since the dwarfness of varieties such as MD and Tom Thumb appears to be too short for present agricultural requirements. 
A question regarding the mode of action of $\mathrm{Gai}_{3}$ raised by Gale and Marshall $(1973 b)$, is answered by the present results. It is clear that $\mathrm{Gai}_{3}$ is almost completely dominant and that in the hemizygous state the gene is as potent as in either the homozygous or heterozygous conditions. Moreover, the absence of $\mathrm{Gai}_{3}$ as in plants nullisomic for $4 \mathrm{~A}$, produces a response to GA, indicating that insensitivity is an active effect rather than the lack of some essential biosynthetic apparatus for processing the hormone as might be expected in the case of a deletion.

Finally a point emerges from this work concerning the theoretical basis for monosomic analysis. As mentioned earlier, it has generally been assumed that $\mathrm{F}_{2}$ families monosomic for the critical chromosome carrying a dominant gene will deviate from the expected $3: 1$ ratio of the control $\mathrm{F}_{2}$ since only the nullisomics, normally expected to be about 3 per cent, will express the recessive phenotype. However, it is evident in the experiment described here, that the critical monosomic family had a frequency of nullisomic progeny of about one-quarter indicating a male transmission rate much higher than previous experience has indicated (Sears, 1953). Interestingly, Morris et al. (1972) obtained similar high frequencies for the same chromosome in the monosomic analysis of dwarfism in Tom Thumb. It is possible that this high transmission rate of nullisomic gametes may be associated with $\mathrm{Gai}_{3}$ or a different locus carried by chromosome 4A. If, however, this proves not to be the case and if such transmission rates were to occur frequently then conventional monosomic analysis may fail to locate other single dominant genes unless efforts are made to check the chromosome counts of $\mathrm{F}_{2}$ monosomic progeny.

\section{REFERENCES}

ALLAN, R. E., AND vOGEL, O. A. 1964. $F_{2}$ monosomic analysis of coleoptile and first-leaf development in two series of wheat crosses. Crop Science, 4, 338-339.

ALLAN, R. E., VOGEL, O. A., AND CRADDOCK, J. C. 1959. Comparative response to gibberellic acid of dwarf, semi-dwarf and tall winter wheat varieties. Agronomy fournal, 51, 737-740.

Austin, R. B., AND mClean, M. s. 1972. A method for screening Phaseolus genotypes for tolerance to low temperatures. F. Hort. Sci., 47, 279-290.

cochran, w. G. I964. Approximate significance levels of the Behrens-Fisher test. Biometrics, 20, 191-195.

GALE, M. D., AND MARSHALl, G. A. 1973a. Insensitivity to gibberellin in dwarf wheats. Annals of Botany, 37, 729-35.

Gale, M. D., AND Marshall, G. A. 1973b. Dwarf wheats and gibberellins. Proceedings of the IVth International Wheat Genetics Symposium 1974, 513-519.

GALE, M. D., AND MARShALL, G. A. 1975. The nature and control of gibberellin insensitivity in the dwarf wheat grain. Heredity (in press).

HU, M. L. 1974. Genetic analyses of semi-dwarfing and insensitivity in gibberellin $\mathrm{GA}_{3}$ in hexaploid wheat. Ph.D. Thesis, Washington State University.

MACER, R. C. F. 1966. The formal and monosomic genetic analysis of stripe rust resistance in wheat. Proceedings of the Second International Wheat Genetics Symposium, Lund 1963. Hereditas, Supplement Vol. 2, 127-142.

MORRIS, R., SCHMIDT, J. W., AND JOHNSON, v. A. 1972. Chromosomal location of a dwarfing gene in "Tom Thumb" wheat derivative by monosomic analysis. Crop Science, 12, 247-249.

RADLEY, M. 1970. Comparison of endogenous gibberellins and response to applied gibberellin of some dwarf and tall wheat cultivars. Planta, 92, 292-300.

SEARS, E. R. 1953. Nullisomic analysis in common wheat. The American Naturalist, 87, 245-252. UNRAU, J. 1950. The use of monosomes and nullisomes in cytogenetical studies of common wheat. Scient. Agric., 30, 66-89.

zeven, A. c. 1969. Tom Pouce Blanc and Tom Pouce Barbu Rouge, two Triticum aestivum sources of very short straw. Wheat Information Service, 29, 8-9. 